\title{
Polyphenol Measurement and Antioxidant Activity of Miracle Fruit
}

\author{
Fang-Yi Cheng, Shyue-Tsong Huang, Mei-Ling Lin, and Jinn-Tsyy Lai
}

\begin{abstract}
Miracle fruit has unique protein which can make sour flavors to sweet, and the bright red skin might be a natural pigment. After the harvest of miracle fruit, removal of fruit skin, fruit meat, the fruit seeds become natural side product using for biofertilizer. Recently, a growing research reports focus on the investigation of fruit seeds for screening potential antioxidants, such as steroids, phenols, and flavonoids as well. In this research, we verity miracle fruit seed is great multi- antioxidant source by different extraction solution. $3 \mu \mathrm{g}(\mathrm{GAE}) / \mathrm{mg}$ total phenolic and $3.1 \mu \mathrm{g}(\mathrm{RUE}) / \mathrm{mg}$ flavonoid content was measured when the miracle fruit was extracted by acetic acid buffer with $20 \mathrm{mM}$ at pH6.0 and pure ethanol. The antioxidation ability of DPPH and ABTS free radical scavenging was over $70 \%$, chelating effect of ferrous ions reached $80 \%$.
\end{abstract}

Index Terms-Miracle fruit, fruit seed, total phenolics, antioxidant activity.

\section{INTRODUCTION}

Miracle Fruit is a kind of cherry plant, original from West Africa, which is also known as Synsepalum dulcificum or Richadella dulcifica. It is also located in the plant kingdom, angiosperm phylum, dicotyledoneae class, ericales order, sapotaceae family, and miracle family according to the plant taxonomy. As one kind of Tropical shrub, this plant in Taiwan is more and more popular. Miracle fruit is known for its miraculin as a sugar substitute. Especially for the diabetes patients, it is really joyful for them to perceive the sweet taste in case of intake of sour compounds. Compared to the regular protein with liable to thermal damage, miraculin is relative stable and make a potential application in preparation of functional food. The sour compound will be perceived as sweet taste after the tongue is exposed to the miraculin environment.

Amid the miracle fruit, the fruit seed plays around $50 \%$. Besides the breeding use, most of the seeds are taken into bio-composting field. However, there are some researches described with the promising use for existence of steroids, phenols, and flavonoids as well [1], [2]. For the demand of aging society, these substances have the ability to overact the free radicals, regulate the immunity, anti-inflammation, cardiovascular protection and cancer prevention. In this research, the miracle fruit seed was extracted by different

Manuscript received May 16, 2014; revised October 9, 2014.

Fang-Yi Cheng, Shyue-Tsong Huang, and Jinn-Tsyy Lai are with the Bioresource Collection and Research Center, Food Industry Research and Development Institute, Hsinchu 30401, Taiwan (e-mail: fyc@firdi.org.tw, sth@firdi.org.tw, jtl@ firdi.org.tw).

Mei-Ling Lin is with the Sen Yuh Farm Science Co., LTD, Kaohsiung 80047, Taiwan (e-mail: senyuh@ seed.net.tw). extraction solution and found out key factors to get maximum total phenolic content. After extraction, we would like to examine the influence of different seed extract on the performance of free radicals scavenging as a basis for derived functional products with miracle fruit.

\section{EXPERIMENTAL}

\section{A. Sample Preparation and Extraction}

The seeds of miracle fruit provided by Sen Yuh Farm Science Co., LTD.

All the samples were treated by lyophilization and ground to a fine powder with the stainless-steel grinder. The powder scale were controlled in 18 mesh units(USA Standard Sieve) and stored in the constant temperature $\left(20^{\circ} \mathrm{C}\right)$ and humidity (47\%RH) chamber.

The extraction was modified by the method of Inglett and Chen [1]. $400 \mathrm{mg}$ sample was homogenously mixed with 20 $\mathrm{mL}$ extraction solution at $25^{\circ} \mathrm{C}$ for one hour. The extract was filtered with Pall membrane filters $(0.45 \mu \mathrm{m})$ and centrifuged at $9000 \mathrm{rpm}$ for $10 \mathrm{~min}$. The supernatants were analyzed for total phenolic content and antioxidant activity.

\section{B. Estimation of Total Phenolic Content in Crude Extracts}

Total phenolic content was determined by the Folin-Ciocalteu colorimetric method [1]. Briefly, $0.1 \mathrm{~mL}$ crude extract supernatants were added with $7.9 \mathrm{~mL}$ deionized water and $0.5 \mathrm{~mL}$ of Folin-Ciocalteu reagent, mixed by rotator for $15 \mathrm{~min}$. $1.5 \mathrm{~mL}$ of sodium carbonate solution $(1.85 \mathrm{M})$ was added and the mixture was incubated at room temperature in the dark for $2 \mathrm{~h}$. The absorbance was determined by a UV-Vis double beam spectrometer (Spectroquant Pharo300, Merck) at $765 \mathrm{~nm}$. The total phenolic content was calculated and expressed as microgram of gallic acid equivalents (GAE) per milligram dry weight of miracle fruit seeds.

\section{Estimation of the Flavonoid Content in Crude Extracts}

The flavonoid content was determined by the aluminum chloride colorimetric assay described in the previous procedure [1]. $0.5 \mathrm{~mL}$ of crude extract supernatants were mixed with $1.5 \mathrm{~mL}$ of $95 \%$ ethanol, $0.1 \mathrm{~mL}$ of $10 \%$ aluminum chloride, $0.1 \mathrm{~mL}$ of $1 \mathrm{M}$ potassium acetate, and $2.8 \mathrm{~mL}$ of deionized (DI) water. After 30min incubated in dark, and centrifuged at $9000 \mathrm{rpm}$ for $10 \mathrm{~min}$. Absorbance was measured at $415 \mathrm{~nm}$. The flavonoid content was expressed as $\mu \mathrm{g}$ rutin equivalents (RUE) per milligram dry weight of miracle fruit seeds.

\section{DPPH Free Radical Scavenging Assay}

The method was modified based on previous procedure [3] 
[4]. A portion of $1.5 \mathrm{~mL}$ of crude extracts supernatant was mixed with $0.5 \mathrm{~mL}$ of $4 \mathrm{mM}$ DPPH and left in the dark for 30 min. The absorbance was measured at $517 \mathrm{~nm}$. A blank was prepared without extract, the ability of DPPH free radical scavenging was calculated by the equation below.

DPPH free radical scavenging $(\%)=A_{\text {blank }}-A_{\text {sample }} / A_{\text {blank }}$ $\times 100$

\section{E. Chelating Effect of Ferrous Ions (FRAP)}

The chelating ability of ferrous ions by the extracts was estimated by the previously reported methods [5], [6]. The crude extract supernatants $(2.5 \mathrm{~mL})$ were mixed with of $2 \mathrm{mM}$ $\mathrm{FeCl}_{2} \cdot 4 \mathrm{H}_{2} \mathrm{O}(0.05 \mathrm{~mL})$. The reaction was initiated by the addition of $0.2 \mathrm{~mL}$ of $5 \mathrm{mM}$ Ferrozine. After the reaction balanced for $10 \mathrm{~min}$, the absorbance was measured at $562 \mathrm{~nm}$ against the blank in the same way using $\mathrm{FeCl}_{2} \cdot 4 \mathrm{H}_{2} \mathrm{O}$ and water. The percentage of chelating ability of ferrous ions was calculated as follows:

Chelating of ferrous ions ability $(\%)=\mathrm{A}_{\text {blank }}-\mathrm{A}_{\text {sample }} / \mathrm{A}_{\text {blank }}$ $\times 100$

\section{F. ABTS Free Radical Scavenging Assay}

The ABTS assay was performed according to a previous study by Arts et al. [7]. ABTS (2,2'-azinobis-(3-ethylbenzoth iazoline-6- sulfonate)) was dissolved in deionized (DI) water to $7 \mathrm{mM}$, the ABTS radical cation was formed by reacting with potassium persulfate $(140 \mathrm{mM})$. After a $12-16 \mathrm{~h}$ incubated in the dark at room temperature, the solution was diluted in ethanol until the absorbance of 0.7 at $734 \mathrm{~nm}$. $25 \mu \mathrm{L}$ of crude extract was added to $1 \mathrm{~mL}$ of $\mathrm{ABTS}^{\cdot+}$ solution and the reaction with the one minute. The absorbance was measured at $734 \mathrm{~nm}$. A blank was prepared without the crude extracts supernatant, the ability of ABTS free radical scavenging was calculated by the equation below.

ABTS free radical scavenging $(\%)=\mathrm{A}_{\text {blank }}-\mathrm{A}_{\text {sample }} / \mathrm{A}_{\text {blank }}$
$\times 100$

\section{RESULTS AND DISCUSSION}

\section{A. Total Phenolic and Flavonoid Content of Miracle Fruit Seed Extracts}

In a previous study, Du Liqing et al. reported total phenolic content of $3.067 \mu \mathrm{g}$ GAE/mg-Fw in the methanolic extracts obtained from miracle fruit seeds [2]. But methanol is not suitable extraction solvent for food application. So in this study, we use sodium acetate buffer and ethanol to extract miracle fruit seed. The results of total phenolic and flavonoid content are shown in Fig. 1. More total phenolic content was extracted by higher $\mathrm{pH}$ sodium acetate buffer. Maximal total phenolic content is $3 \mu \mathrm{g}$ GAE/mg seeds when buffer $\mathrm{pH}$ is 6.0 . But sodium acetate buffer was useless for extraction of flavonoid form miracle fruit seeds.

Besides, extra ethanol was mixed with $\mathrm{pH} 6.0$ sodium acetate buffer to extract, In Fig. 2 total phenolic content was obviously reduced when over $50 \%(\mathrm{v} / \mathrm{v})$ ethanol in solution. Minimal total phenolic content is $1.26 \mu \mathrm{g}$ GAE/mg miracle fruit seeds by pure ethanol extraction. But total flavonoid content was rapid increase in the $90-100 \%$ ethanol, and maximal flavonoid content in pure is $3.1 \mu \mathrm{g}$ RUE $/ \mathrm{mg}$.

In previously study, used $50 \%$ ethanol and methanol to extract the miracle seeds, the flavonoid content was $0.04 \mu \mathrm{g}$ $\mathrm{RUE} / \mathrm{mg}$ and $0.038 \mu \mathrm{g}$ QUE $/ \mathrm{mg}$, respectively. In this study, we obtained tenfold the flavonoid content.

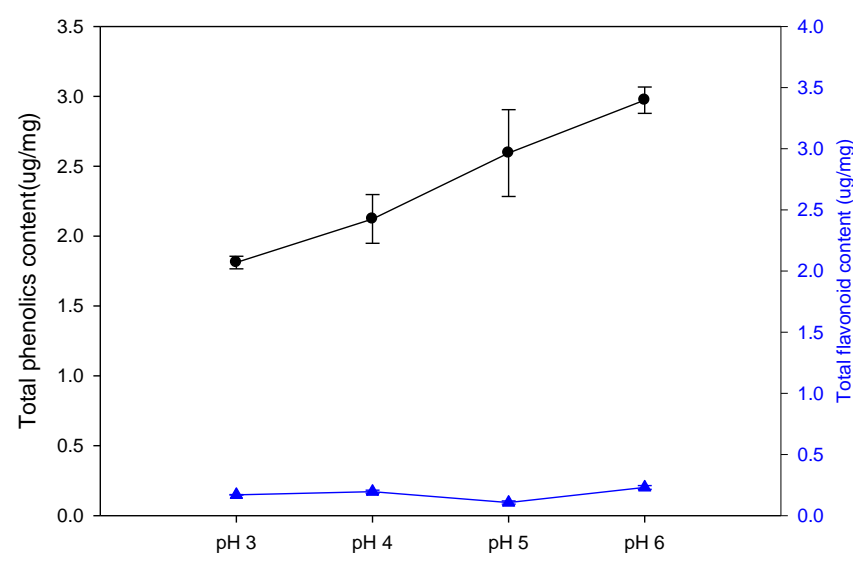

Fig. 1. Total phenolic $(\bullet)$ and flavonoid $(\mathbf{\Lambda})$ content of miracle fruit seeds extract by different $\mathrm{pH}$ sodium acetate buffer.

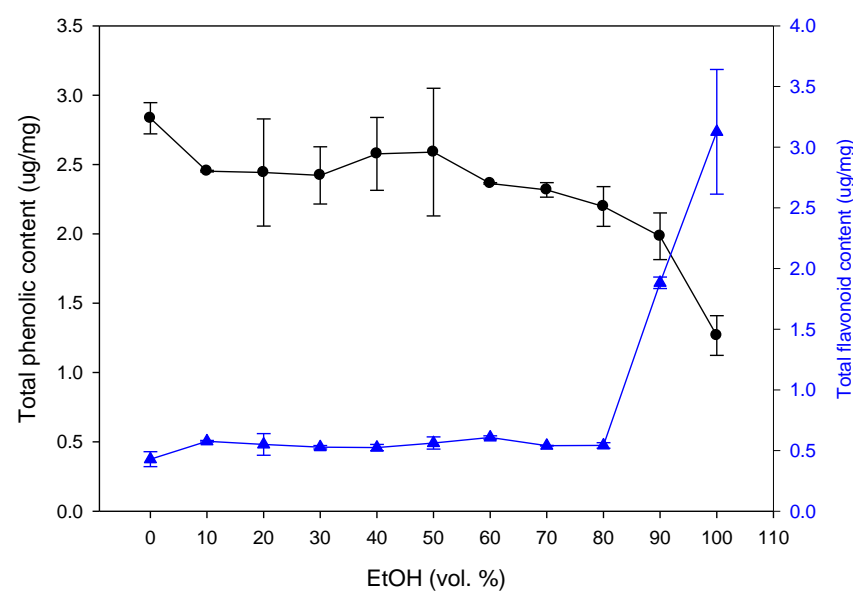

Fig. 2. Total phenolic $(\bullet)$ and flavonoid $(\mathbf{\Delta})$ content of miracle fruit seeds extract by mix different ratio sodium acetate buffer and ethanol.

\section{B. The Antioxidant Ability of Miracle Fruit Seeds Extract in DPPH Free Radical Scavenging}

The antioxidant inhibit oxidation chain reaction by providing hydrogen donor for peroxyl radical. Normally, we select DPPH as free radical to evaluate the ability as hydrogen donor of antioxidant. DPPH has strongly absorption at 517 nm. More potential of antioxidant offer hydrogen, the less absorb of DPPH at $517 \mathrm{~nm}$. The DPPH test results are shown in Fig. 3. Higher buffer $\mathrm{pH}$ with higher DPPH free radical scavenging ability. The radical scavenging ability of $\mathrm{pH} 6.0$ sodium acetate buffer and $50 \%$ ethanol mixed solution was over $80 \%$, suppose this result is related to total phenolic content. But pure ethanol extract also has very impressive presented with DPPH free radical scavenging ability, suppose this result is related to high flavonoid content in pure ethanol extract. Du Liqing et al. and Inglett and Chen reported the DPPH free radical scavenging of the miracle fruit seed extracts are 54.3 and $49.45 \%$ [1], [2], and in this study, we observed higher antioxidant ability. 


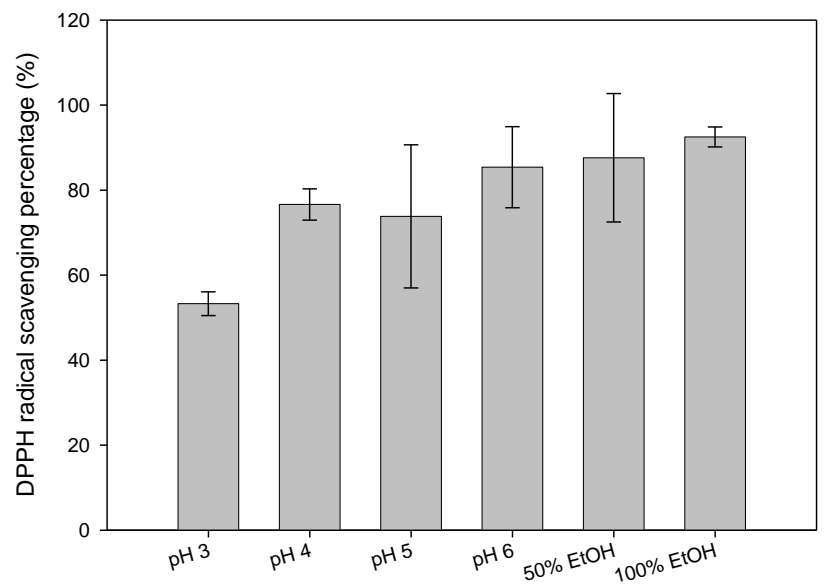

Fig. 3. The free radical scavenging percentages of the miracle fruit seed extracts in DPPH.

\section{The Antioxidant Ability of Miracle Fruit Seeds Extract in Chelating Effect of Ferrous Ions (FRAP)}

Highly oxidant potential of metal ion is one of factor of lipid peroxidation. A metal ion can provided sufficient free radical and cause oxidative degradation of lipids. For instance, $\mathrm{Fe}$ (II) will provide enough free radical and accelerate oxidation process. Therefore, we can prevent free radical induced lipid peroxidation form metal ions by using chelating agent as an antioxidant selection. The ability of chelating Fe (II) of miracle fruit seed crude extracts in Fig. 4. Higher $\mathrm{pH}$ sodium acetate buffer with higher ability of chelating Fe (II). But pure ethanol extract had maximal ability in this test, suppose this result is related to high flavonoid content in pure ethanol extract.

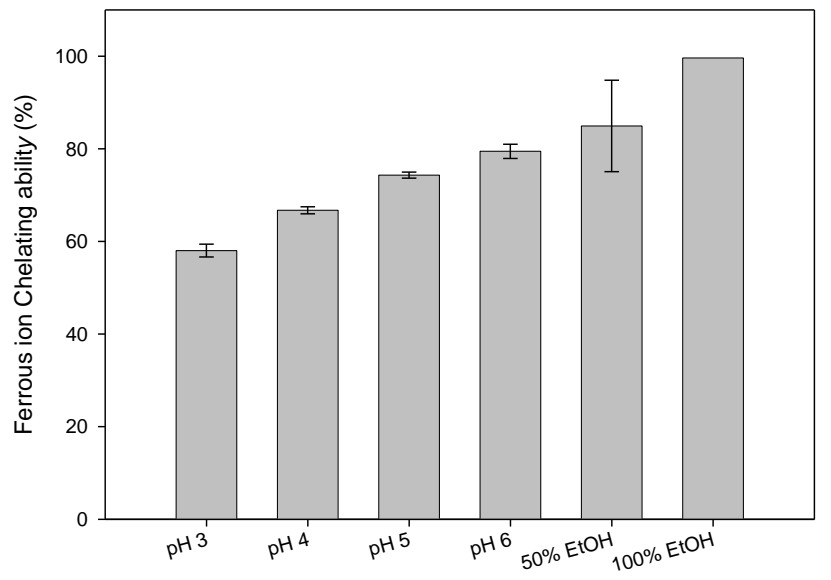

Fig. 4. The ferrous ion (Fe (II)) chelating ability of the miracle fruit seed extracts.

\section{The Antioxidant Ability of Miracle Fruit Seeds Extract in ABTS Free Radical Scavenging}

The ABTS free radical scavenging ability is based on the intensity of an antioxidant in scavenging the radical cation generated by ABTS. When antioxidant is reactive towards the ABTS radical cation, the reaction solution will turn blue to colorless. A positive relationship between the $\mathrm{pH}$ value of miracle fruit seeds extract solution and ABTS free radical scavenging. The ABTS ability was more than $70 \%$ of miracle fruit seed crude extract supernatants by using sodium acetate buffer (pH 6.0) and 50\% ethanol as extraction solvents(Fig. $5)$, which was triple that of the previous report (18\%) [2].
When we was replaced sodium acetate buffer with pure ethanol, the antioxidant ability was obvious decreased. The results shown that ABTS ability was consistent with the total phenolic content, pure ethanol extract with high flavonoid content but no obvious effect in ABTS assay.

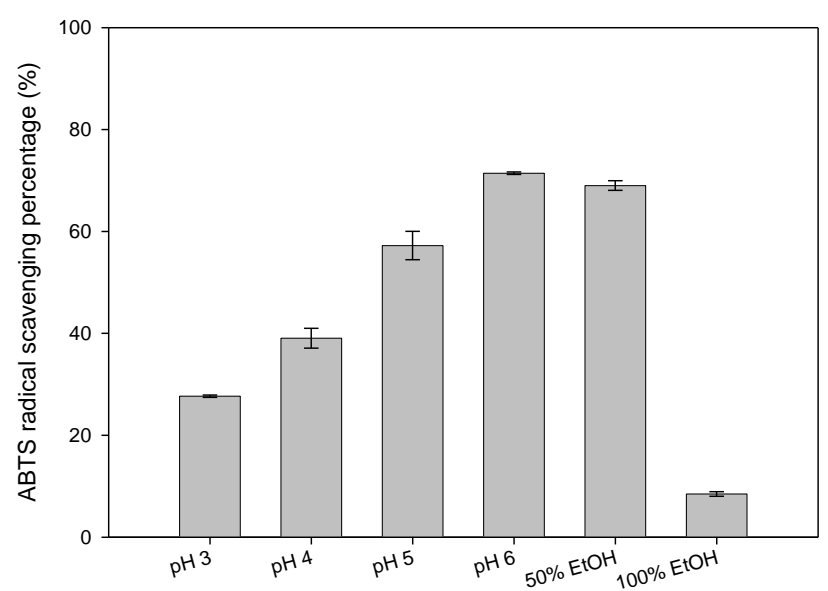

Fig. 5. The free radical scavenging percentages of the miracle fruit seed extracts in ABTS.

\section{CONCLUSIONS}

Many researches described miracle fruit seed with the promising use for existence of steroids, phenols, and flavonoids as well. In this study, total phenolic and flavonoid was extracting by sodium acetate buffer and pure ethanol. More total phenolic content was extracted when increase with the sodium acetate buffer $\mathrm{pH}$ value. However the flavonoid content extracted was increased with the ethanol ratio.

The DPPH, FRAP and ABTS assay results verify that miracle fruit seed extracts were powerful antioxidant. The antioxidant activity of miracle fruit seed extract by sodium acetate buffer is related to total phenolic content. But although total phenolic content is low in pure ethanol extracts, it still shows obvious DPPH and FRAP activity. So we believe miracle fruit seed is great multi-antioxidant source. In the future, establish optimal extraction process and identify phenolic and the flavonoid compounds in the miracle fruit seed extracts is the key to provide health promoting function.

\section{REFERENCES}

[1] G. E. Inglett and D. Chen, "Contents of Phenolics and flavonoids and antioxidant activities in skin, pulp, and seeds of miracle fruit," Journal of Food Science, vol. 76, no. 3, pp. 479-482, 2011.

[2] L. Du, Y. Shen, X. Zhang, W. Prinyawiwatkul, and Z. Xu, "Antioxidant-rich phytochemicals in miracle berry (Synsepalum dulcificum) and antioxidant activity of its extracts," Food Chemistry, vol. 153 , no. 15 , pp. $279-284,2014$

[3] D. M. Nagmoti, D. K. Khatri, P. R. Juvekar, and A. R. Juvekar, "Antioxidant activity free radical-scavenging potential of Pithecellobium dulce Benth seed extracts," Free Radicals and Antioxidants., vol. 2, no. 2, pp. 37-43, 2012.

[4] P. Senthilkumar and S. Sudha, "Antioxidant and Antibacterial Properties of Methanolic Extract of Green Seaweed Chaetomorpha linum From Gulf of Mannar: Southeast Coast of India," Jundishapur J. Microbiol., vol. 5, no. 2, pp. 411-415, 2012.

[5] N. Ozsoy, A. Can, R. Yanardag, and N. Akev, "Antioxidant activity of Smilax excelsa L. leaf extracts," Food Chemistry., vol. 110, no. 3, pp. 571-583, 2008.

[6] L. Sun, J. Zhang, X. Lu, L. Zhang, and Y. Zhang, "Evaluation to the antioxidant activity of total flavonoids extract from persimmon 
(Diospyros kaki L.) leaves," Food and Chemical Toxicology., vol. 49, no. 10, pp. 2689-2696, 2011.

[7] M. J. T. J. Arts, J. S. Dallinga, H. P. Voss, G. R. M. M. Haenen, and A. Bast, "A new approach to assess the total antioxidant capacity using the TEAC assay," Food Chemistry, vol. 88, no. 4, pp. 567-570, 2004

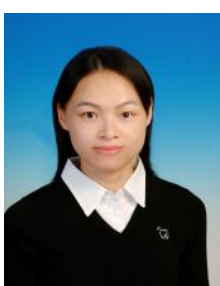

Fang-Yi Cheng was born in Taiwan at Taoyuan. She graduated from the Department of Chemical Engineering of National Taipei University of Technology in 1998 and got her master degree of Chemical Engineering from National Chung Hsing University in 2004.

Now, she is working in the Food Industry Research and Development Institute (FIRDI), she has been an associate research scientist based on process research and product development since 2004
Mei-Ling Lin was born in Taiwan, who got a bachelor's degree and won a master's degree as well in chemistry from Providence University in 1986 and 1988 , respectively. Over the past years, she has devoted herself to expanding the benefit for healthcare industry, particularly in both academic research and commercial management to miracle fruit.

Now, she is the president of Sen Yuh Farm Science Co., Ltd, which is located in Kaohsiung. Up to the present, she has cultivated over 35,000 miracle trees, and the production capacity reaches $35,000 \mathrm{~kg}$ annually. For the development of more promising product to her business, Miss Lin also made a lot of effort to receive a few patents from Taiwan, Japan, and mainland China as well, such as I299979, I362267 (Taiwan), 4300335 (Japan), and 570209 (China). Moreover, some new frontier food technologies are still run continuously, and those achievements earn her respect and admiration. 